\title{
Solid Phase Microextraction (SPME) Fibers: in situ Measurements of Endocrine Disrupting Chemicals in Seawater
}

\author{
Dayana M. Santos, ${ }^{a, b}$ Mike Williams, ${ }^{c}$ Rai Kookana ${ }^{c}$ and Mary R. R. de Marchi*,a \\ ${ }^{a}$ Instituto de Química, Universidade Estadual Paulista (UNESP), 14800-900 Araraquara-SP, Brazil \\ ${ }^{b}$ Departamento de Química, Universidade Estadual de Londrina (UEL), 86057-970 Londrina-PR, Brazil \\ ${ }^{c}$ CSIRO Land and Water, Urrbrae, 5064 Adelaide, South Australia, Australia
}

\begin{abstract}
A study involving microextraction fibers was carried focusing on calibration setup for endocrine disrupting chemicals (EDCs) sorption in seawater. The sorption of EDCs (triclosan (TCS), bisphenol A (BPA) and 17 $\alpha$-ethinylestradiol (EE2)) were checked using acrylate, nylon and polydimethylsiloxane (PDMS) fiber coating with 5 and $1 \mathrm{~cm}$ length after 7 days of exposure. Extracts were determined by liquid chromatography tandem mass spectrometry (LC-MS/MS). Comparing with previous studies, results indicate a promising use of this device for field monitoring as well as for bioavailability studies mimicking the organism uptake from environment.
\end{abstract}

Keywords: passive sampler, endocrine disrupting chemicals, seawater, acrylate fiber

\section{Introduction}

Endocrine disrupting compounds (EDCs) are commonly found in aquatic systems mainly as result of wastewater treatment discharges where they can reach all compartments due to the broad range of physicochemical properties. In this context, organisms are in contact with these contaminants through these different compartments ${ }^{1-3}$ where the assimilation/uptake can occur through active and passive mechanisms. ${ }^{4}$

Bioavailability is a dynamical process involving exposure time and intensity considering physical, chemical and biological interactions including association/ dissociation, transport and uptake. ${ }^{5}$ To check bioavailability in absence of a biomonitoring organism or even for monitoring contaminant levels in aquatic environments, many devices, known as passive samplers, have been tested. ${ }^{6}$ In the field, the volume of water sample necessary for reach detectable levels in laboratory analysis are quite high, where spatial and temporal variations can bring logistical and reliability difficulties for the monitoring process. ${ }^{7-9}$ POCIS (polar organic chemical integrative sampler) is one of the most common passive sampler used for organic microcontaminants in water phase and, besides quantitative analysis, can also offer an estimative

*e-mail: mssqam@iq.unesp.br of contaminants uptake through gills exposure of aquatic organisms. ${ }^{7,10}$ For contaminants with a lipophilic profile a semi-permeable membrane device (SPMD) is also described for water ${ }^{10,11}$ and sediment matrices. ${ }^{9}$ Besides the loss of field variability, the use of passive samplers can reduce the natural variability of exposed organisms in bioavailability assays. ${ }^{12}$

Another device, the solid phase microextraction (SPME), has been also tested as passive sampler. This device is based on a chemical partitioning between aqueous and polymeric phase available in a small amount. ${ }^{13}$ It is traditionally used for organic micropollutants determination in aqueous phase, but it can also be applied for porewater concentrations if equilibrium time is taken into account. ${ }^{14,15}$ Non depletive SPME studies are also described, where the partitioning equilibrium is not disturbed and the adsorption can mimic organism uptake. ${ }^{16}$ Sensibility of SPME sampler is directly related with the compound $\mathrm{K}_{\text {ow }}$ (octanol-water partition coefficient) and increases with sorbent volume $\left(\mathrm{V}_{\mathrm{f}}\right),{ }^{17}$ and is mainly applied to evaluate the uptake of hydrophobic organic compounds (HOCs) as polycyclic aromatic hydrocarbons (PAHs) and polychlorinated biphenyls (PCBs), but also contaminants of emerging concern as polybrominated diphenyl ethers (PBDEs). ${ }^{6}$ SPME compositions can include polyacrylate fibers, composed by esterified acrylate and with unspecific interactions with alcoholic, phenolic and amine groups. 
For sediments/porewater matrix glass fibers coated with polydimethylsiloxane (PDMS) was previously investigated due to the fast sorption medium avoiding chemical equilibrium disturbance ${ }^{18}$ and applied in PAH monitoring. ${ }^{19}$ In water phase PDMS fibers are also applied for pyrethroids analysis. $^{20}$

The aim of this study was to check the uptake capacity of three different polymeric microfibers composition as promising passive sampler device for EDCs monitoring in situ or even in bioavailability studies. The knowledge about fiber-water partitioning $\left(\mathrm{K}_{\mathrm{f}}\right)$, essential to understand the aqueous phase concentration, mass balance, degradation rate and depletion capacity were checked in this study. In this sense, it was investigated the interaction of freely-dissolved EDCs in artificial seawater with fibers during seven days and the assessment of uptake rate and deployment that can be used for follow up studies.

\section{Experimental}

\section{Materials}

Standards triclosan (TCS) and bisphenol A (BPA) were purchased from Sigma-Aldrich (Castle Hill, NSW, Australia) and $17 \alpha$-ethynylestradiol (EE2) was purchased from ScyVac Pty Ltd. (NSW, Australia). Acetonitrile, dichloromethane, methanol, acetic acid and vials were purchased from Thermo Fisher Scientific (Scoresby, Vic, Australia). Propyleneglycol were purchased from Sigma-Aldrich (Castle Hill, NSW, Australia). Polymeric microfibers were obtained as courtesy from Fiberguide Industries (Stirling, NJ, USA).

\section{Endocrine disrupting chemicals (EDCs)}

The physical-chemical properties of the investigated EDCs: the antimicrobial triclosan (TCS), the plasticizer bisphenol A (BPA) and the synthetic hormone $17 \alpha$-ethynilestradiol (EE2), are demonstrated in Table 1.

Theory

The use of passive samplers includes a range of laboratory parameters to be considered..$^{13,17,18}$ One of them is the mass balance of the system that can be described as follows the equation 1 .

$\mathrm{N}^{\mathrm{o}}{ }_{\mathrm{w}}=\mathrm{N}_{\mathrm{w}}+\left(\mathrm{N}^{\mathrm{o}}{ }_{\mathrm{w}}-\mathrm{b}\right)+\mathrm{N}_{\mathrm{f}}$

where: $\mathrm{N}^{\circ}$ w and $\mathrm{N}_{\mathrm{w}}$ are the initial and final concentration in water phase $\left(\mathrm{ng} \mathrm{mL} \mathrm{m}^{-1}\right)$, respectively; $\mathrm{b}$ is the degradation rate measured on spiked seawater without the fiber presence ( $\mathrm{ng} \mathrm{mL} \mathrm{mL}^{-1}$ ); $\mathrm{N}_{\mathrm{f}}$ is the concentration in fiber ( $\mathrm{ng} \mathrm{mL}^{-1}$ ).

After the contact period is possible to check the depletion capacity of the fiber as follows on equation 2 .

$\mathrm{X}_{\mathrm{e}}=\left(\mathrm{C}^{\mathrm{o}}{ }_{\mathrm{w}}-\mathrm{C}_{\mathrm{w}}\right) / \mathrm{C}^{\mathrm{o}}{ }_{\mathrm{w}}$

where $\mathrm{X}_{\mathrm{e}}$ is the depletion capacity of the fiber; $\mathrm{C}^{\mathrm{o}}{ }_{\mathrm{w}}$ and $\mathrm{C}_{\mathrm{w}}$ are the initial and final concentration in water $\left(\mathrm{ng} \mathrm{mL}^{-1}\right)$, respectively.

For a non depletive SPME, a depletion of 0.05 is suggested as a threshold. ${ }^{18}$ In this procedure, it is also important to determine the volume of fiber once this parameter can affect directly the sorption surface of interaction and is calculated according to the equation 3 .

Table 1. Properties of endocrine disrupting chemicals investigated in this study. Source: Bayen et al..$^{21}$

\begin{tabular}{|c|c|c|c|c|c|c|c|}
\hline & CAS & $\begin{array}{c}\text { M.W. / } \\
\left(\mathrm{g} \mathrm{mol}^{-1}\right)\end{array}$ & $\begin{array}{c}\text { Solubility / } \\
\left(\mathrm{mg} \mathrm{L}^{-1}\right)\end{array}$ & $\mathrm{p} K_{\mathrm{a}}$ & $\begin{array}{c}\log \mathrm{K}_{\mathrm{ow}} \\
(\mathrm{pH} 8)\end{array}$ & $\log \mathrm{K}_{\mathrm{oc}}$ & $\begin{array}{c}1 / 2 \text { life } / \\
\text { days }\end{array}$ \\
\hline Triclosan & $3380-34-5$ & 289.5 & 9.29 & 7.8 & 5.06 & 4.37 & 60 \\
\hline Bisphenol A & $80-05-7$ & 228.3 & 172.7 & 9.5 & 4.24 & 4.57 & 37.5 \\
\hline $17 \alpha$-Ethynylestradiol & $57-63-6$ & 296.41 & 13.2 & 10.4 & 4.66 & 4.65 & 60 \\
\hline
\end{tabular}

M.W.: molecular weight; $\mathrm{K}_{\mathrm{ow}}$ : octanol-water partition coefficient; $\mathrm{K}_{\mathrm{oc}}$ : organic carbon distribution coefficient. 
$\mathrm{V}_{\mathrm{f}}=\pi \mathrm{L} \times\left(\mathrm{R}^{2}-\mathrm{r}^{2}\right)$

where: $\mathrm{V}_{\mathrm{f}}$ is the fiber volume $\left(\mu \mathrm{L} \mathrm{m}^{-1}\right)$; $\pi \mathrm{L}$ the length of fiber $(\mu \mathrm{m})$; $\mathrm{R}$ and $\mathrm{r}$ are the radius of fiber and glass core, respectively.

Through this value $\left(\mathrm{V}_{\mathrm{f}}\right)$ and after exposure time, it is possible to calculate the fiber water partitioning coefficient $\left(\mathrm{K}_{\mathrm{f}}\right)$ using the equation 4.

$\mathrm{K}_{\mathrm{f}}=\left(\mathrm{N}_{\mathrm{f}} \mathrm{V}_{\mathrm{f}}\right) /\left(\mathrm{V}_{\mathrm{w}} \mathrm{N}_{\mathrm{w}}\right)$

where: $\mathrm{K}_{\mathrm{f}}$ is the fiber partitioning coefficient; $\mathrm{N}_{\mathrm{f}}$ the concentration in fiber $\left(\mathrm{ng} \mathrm{mL}^{-1}\right) ; \mathrm{V}_{\mathrm{f}}$ the fiber volume $\left(\mu \mathrm{L} \mathrm{m}^{-1}\right) ; \mathrm{V}_{\mathrm{w}}$ the water volume $(\mathrm{mL}) ; \mathrm{N}_{\mathrm{w}}$ the concentration in water $\left(\mathrm{ng} \mathrm{mL} \mathrm{mL}^{-1}\right)$.

Setup

Polymeric microfibers with 3 different coatings (jacket) were tested on this calibration experiment (Figure 1). Fibers with 1 and $5 \mathrm{~cm}$ lengths were selected considering the $\mathrm{V}_{\mathrm{f}}$ $\left(\mu \mathrm{L} \mathrm{m}^{-1}\right)$ demonstrated on Table 2 . Artificial seawater with salinity of 31 psu was prepared for experiments. ${ }^{22}$ All fibers were cut in specific lengths, washed 3 times with methanol and stored in scintillation vials containing Milli-Q water until use. Glassware and instruments (tweezers, scissors) were washed with neutral detergent and tap water, rinsed with Milli-Q water and acetone and kilned at $350{ }^{\circ} \mathrm{C}$ by $3 \mathrm{~h}$. Sodium azide ( $1 \mathrm{mM}$ ) was also used in this experiment to reduce microbial degradation of compounds during the experiment. $^{23}$

Three different coating fibers with $5 \mathrm{~cm}$ length were selected for exposure to EDCs in seawater with measurements in 24, 72 and $168 \mathrm{~h}$ (7days). Vials containing immersed fibers were kept in the dark at a constant temperature, shaking in an orbital shaker at $115 \mathrm{rpm}$ for interaction. The tested concentrations were $0.1 \mathrm{mg} \mathrm{L}^{-1}$ for BPA and EE2 and $1 \mathrm{mg} \mathrm{L}^{-1}$ for TCS. At the same time, it was also tested TCS sorption using $1 \mathrm{~cm}$ fiber exposed to a $1 \mathrm{mg} \mathrm{L}^{-1}$ of this contaminant. Each fiber was exposed

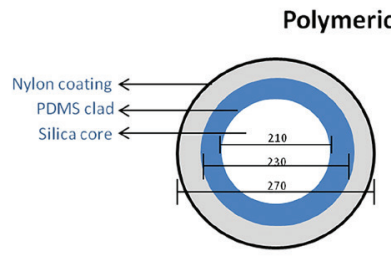

(a)

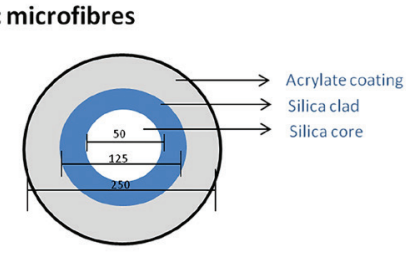

(b)
Figure 1. Polymeric microfibers. (a): Nylon coating with PDMS clad; (b): acrylate coating. Diameters in micrometers $(\mu \mathrm{m})$.

to $20 \mathrm{~mL}$ spiked seawater following the procedures adapted from Lao et al. ${ }^{20}$ for pyrethroid/PDMS fiber two compartment mass balance in aqueous phase; Yang et al..$^{13}$ for hydrophobic organic chemicals/PDMS fiber calibration setup; and Haftka et al. ${ }^{24}$ for ionic organic contaminants/ polyacrylate fiber calibration setup. The procedure adopted in the present study differs from cited references mainly in terms of fiber composition, length and tested chemicals. All experiment was conducted in duplicate. Quality control was check using vials containing spiked seawater without fiber to check degradation rate as well as procedural blanks. The $\mathrm{pH}$ measurements during 7 days exposure were $8.31 \pm 0.07$.

To allow the use of PDMS cover it was necessary to remove the nylon layer from this fiber. For this, we heated propylene glycol to $180{ }^{\circ} \mathrm{C}$, dipped the fiber into solution for approximately $20 \mathrm{~s}$, wiped off using a kimwipe tissue, and then rinsed with Milli-Q water and fibers were stored in Milli-Q water until use. To make sure about the nylon removal, fibers were observed using an optical microscope $(40 \times)$.

Liquid chromatography tandem mass spectrometry (LC-MS/MS) analysis and quality control

After equilibrium/sorption experiment, EDCs in fibers were extracted with $5 \mathrm{~mL}$ of acetonitrile, using $30 \mathrm{~s}$ vortex and $10 \mathrm{~min}$ ultrasonic bath and them left overnight for interaction. ${ }^{24}$ In the following day, the extract was transferred to a new culture tube, re-extracted with $2 \times 2.5 \mathrm{~mL}$ acetonitrile, blown down in $\mathrm{N}_{2}$ stream, and reconstituted with methanol in a vial for LC-MS/MS

Table 2. Volume of fiber $\left(\mathrm{V}_{\mathrm{f}}\right)$, fiber coating composition and length

\begin{tabular}{|c|c|c|c|}
\hline Coating & Composition (dimension / $\mu \mathrm{m})$ & Fiber length / cm & $\mathrm{V}_{\mathrm{f}} /\left(\mu \mathrm{L} \mathrm{m}^{-1}\right)$ \\
\hline \multirow[t]{2}{*}{ Acrylate } & silica/silica/acrylate $(50 / 125 / 250)$ & 1 & 0.98 \\
\hline & & 5 & 4.9 \\
\hline \multirow[t]{2}{*}{ Nylon } & silica/PDMS/nylon (210/230/270) & 1 & 0.5 \\
\hline & & 5 & 2.5 \\
\hline \multirow[t]{2}{*}{ PDMS } & silica/PDMSa (210/230) & 1 & 0.14 \\
\hline & & 5 & 0.72 \\
\hline
\end{tabular}

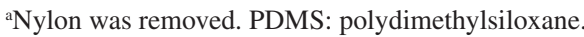


analysis. For seawater analysis, an aliquot of $1 \mathrm{~mL}$ was transferred to a vial, filtered using $0.2 \mu \mathrm{m}$ PTFE (polytetrafluoroethylene) filter and injected.

Compounds were determined using an LC-MS/MS (Thermo Finnigan TSQ Quantum Discovery Max) with two ionization sources: ESI (electrospray ionization in positive and negative mode) for TCS, and APCI (atmospheric pressure chemical ionization) for EE2 and BPA. For ESI, it was used an Atlantis T3 column $(2.1 \times 100 \mathrm{~mm}, 3 \mu \mathrm{m}$, C18 surface coverage $\left.\left(\mu \mathrm{mol} \mathrm{m} \mathrm{m}^{-2}\right)\right)$, with injection volume of $10 \mu \mathrm{L}$ in a flow rate of $300 \mu \mathrm{L} \mathrm{min}{ }^{-1}$ and mobile phase of acetonitrile (A) and $0.1 \%$ formic acid in Milli-Q water (B) in gradient mode (solvent A 5\%, 2 min; $80 \%$ at $3 \mathrm{~min}$; $98 \%$ from 4 to $14 \mathrm{~min}$; and $5 \%$ until $15 \mathrm{~min}$ ). For APCI, the used column was a Hypersil C18 Phenomenex with mobile phase of methanol and Milli-Q water in the same gradient mode described above for ESI mobile phase.

During the experiments a matrix (seawater) and method blanks were considered for quantification. For the injections, quality control was checked using QC standards (intermediary level of calibration curve) between samples through sample list and calibration curves were injected in the beginning and at the end of each sample list. Linearity was above 0.99 for all compounds in a range of 5 to $1000 \mathrm{ng} \mathrm{mL}^{-1}$ and the limits of detection (LOD) were: 111, 177, $88 \mathrm{pg}$ (picograms) for TCS, BPA and EE2, respectively. Matrix effect was checked involving calibration curves $(n=7)$ prepared in solvent (methanol) and artificial seawater. The difference obtained between angular coefficients was below $10 \%$, demonstrating no significant matrix effect.

\section{Results and Discussion}

The interaction behavior of tested compounds with fibers was related with their physical-chemical properties where different responses could be observed. As result, a positive correlation (0.993) was observed, considering the $\log \mathrm{K}_{\mathrm{f}}$ and $\log \mathrm{K}_{\mathrm{ow}}$ for each compound. In this way, when polarity is reduced (increase of hydrophobicity) there is an enhancement of sorption on fibers. Mass balance was between 105 and $123 \%$ for TCS; 97 and $111 \%$ for BPA, 91 and $102 \%$ for EE2 and the results are in agreement with a good calibration quality control. Degradation rate during the experiment was between $30-40 \%$ during the 7 days experiment, despite the addition of sodium azide.

Adsorption percentage for each fiber composition can be observed in Figures $2 \mathrm{a}-2 \mathrm{c}$ as well as the test involving $1 \mathrm{~cm}$ fibers for TCS (Figure 2d). Acrylate fibers demonstrate the best sorption performance and repeatability (relative standard deviation $(\mathrm{RSD})<20 \%$ ), followed by nylon and
PDMS coating for TCS. For BPA and EE2, good results were also observed using acrylate fibers and no sorption for PDMS fibers. Equilibrium time $\left(\mathrm{t}_{\mathrm{eq}}\right)$ between aqueous and $5 \mathrm{~cm}$ acrylate fiber can demonstrate a plateau after 7 days experiment. However, due to the absence of enough points $(n=3)$ to trace a curve, further studies must be done to investigate this interaction uptake, mainly in the first 24 h. In previous studies for triclosan and bisphenol A, Haftka et al. ${ }^{24}$ have observed similar results using polyacrylate fibers in freshwater with different amounts of dissolved organic carbon (DOC) for TCS and BPA. For more hydrophobic compounds, as pesticides, Yang et al. ${ }^{13}$ found $\mathrm{at}_{\mathrm{eq}}$ between 20-30 days using a PDMS coating fiber.

As mentioned above, for TCS, the highest affinity was observed with acrylate coated fibers, followed by nylon and PDMS coating. Results about concentration in fiber (ng), $\log \mathrm{K}_{\mathrm{f}}$ and depletion rate $\left(\mathrm{X}_{\mathrm{e}}\right)$ for this EDC can be observed in Table 3 and tests for 1 and $5 \mathrm{~cm}$ are involved. This major adsorption observed for acrylate coating fibers can be a result of its stronger hydrogen acceptor than PDMS, favorable for molecules with moderate hydrophobicity $\left(\log \mathrm{K}_{\mathrm{ow}}>2.5\right) .{ }^{24}$ After 7 days interaction, sorption was about 80, 33 and $39 \%$ and depletion rate of 90, 22 and $20 \%$ for TCS, EE2 and BPA, respectively, using $5 \mathrm{~cm}$ acrylate fibers. For TCS and BPA, Haftka et al..$^{24}$ found about $60-70$ and $18 \%$, respectively, using $4 \mathrm{~cm}$ polyacrylate coated fibers. However, due to differences on coating thickness, in that study the average $\log \mathrm{K}_{\mathrm{f}}$ were higher (5.58) than that one found in the present study for $5 \mathrm{~cm}$ (1.99) or $1 \mathrm{~cm}$ (1.4) length, even when normalized by the fiber size. Results obtained in a mixture system (TCS containing also BPA and EE2) and alone (only TCS-1 cm fiber), had demonstrated similar results in most aspects, indicating that the presence of other compounds in the system does not affect TCS sorption in acrylate fibers.

The relationship between organisms uptake and the amount adsorbed in passive samplers have been reported. ${ }^{12}$ The main reason of this comparison is the bioavailability of hydrophobic contaminants being similar with bioaccessibility detected in passive samplers. Other issues of contaminant uptake, transformation and depuration certainly exist, that can only be observed using organisms. However, the freely dissolved fraction of these contaminants in water column as well as sediment and porewater can be estimated using these devices. ${ }^{16}$ Studies involving bioconcentration of TCS from water phase in mussels (Mytilus galloprovincialis) exposed to $1 \mu \mathrm{g} \mathrm{L} \mathrm{L}^{-1}$ had demonstrated a plateau after 7 days exposure. ${ }^{25}$ The same behavior was also observed for fish (Poecilia vivipara) exposed to TCS, where the steady-state was around 7-14 days. ${ }^{26}$ Although in different concentration and using an SPME fiber, the adsorption of TCS in acrylate 

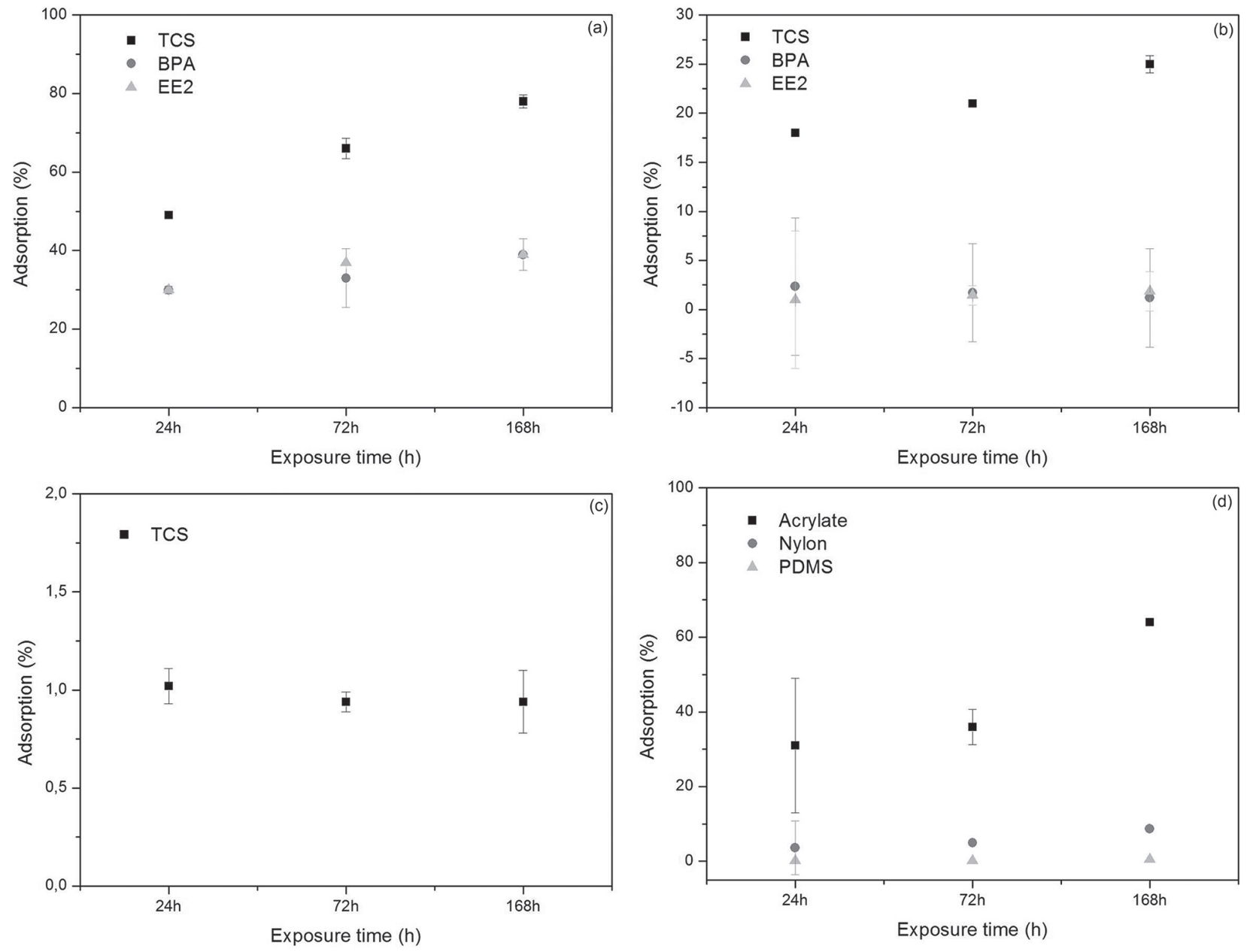

Figure 2. Adsorption percentage in different $5 \mathrm{~cm}$ fiber composition: (a) acrylate; (b) nylon; (c) PDMS; and (d) $1 \mathrm{~cm}$ fiber for triclosan exposure.

Table 3. Concentration in fiber $\left(\mathrm{C}_{\mathrm{f}}\right) \pm \mathrm{RSD}, \log \mathrm{K}_{\mathrm{f}}$ and depletion rate $\left(\mathrm{X}_{\mathrm{e}}\right)$ obtained for 1 and $5 \mathrm{~cm}$ fibers exposed to TCS $1 \mathrm{mg} \mathrm{L}^{-1}$

\begin{tabular}{|c|c|c|c|c|c|c|}
\hline & \multicolumn{3}{|c|}{ TCS $-5 \mathrm{~cm}$} & \multicolumn{3}{|c|}{ TCS $-1 \mathrm{~cm}$} \\
\hline & $\mathrm{C}_{\mathrm{f}} \pm \mathrm{RSD} / \mathrm{ng}$ & $\log \mathrm{K}_{\mathrm{f}}$ & $\mathrm{X}_{\mathrm{e}} / \%$ & $\mathrm{C}_{\mathrm{f}} \pm \mathrm{RSD} / \mathrm{ng}$ & $\log \mathrm{K}_{\mathrm{f}}$ & $\mathrm{X}_{\mathrm{e}} / \%$ \\
\hline \multicolumn{7}{|c|}{ Acrylate } \\
\hline $24 \mathrm{~h}$ & $9806 \pm 3.7$ & 1.63 & 75 & $6329 \pm 18$ & 1.14 & 51 \\
\hline $72 \mathrm{~h}$ & $13252 \pm 5.9$ & 2.03 & 86 & $7245 \pm 4.7$ & 1.34 & 63 \\
\hline $168 \mathrm{~h}$ & $15752 \pm 2.8$ & 2.33 & 90 & $12898 \pm 0.5$ & 1.72 & 73 \\
\hline \multicolumn{7}{|l|}{ Nylon } \\
\hline $24 \mathrm{~h}$ & $3629 \pm 5.09$ & 0.84 & 43 & $722 \pm 7.2$ & 0.06 & 28 \\
\hline $72 \mathrm{~h}$ & $4296 \pm 5.4$ & 0.93 & 45 & $989^{a}$ & 0.18 & 30 \\
\hline $168 \mathrm{~h}$ & $5081 \pm 13.7$ & 1.02 & 48 & $1739^{a}$ & 0.41 & 27 \\
\hline \multicolumn{7}{|l|}{ PDMS } \\
\hline $24 \mathrm{~h}$ & $204 \pm 8.9$ & 0.54 & 23 & $45^{\mathrm{a}}$ & 1.16 & 25 \\
\hline $72 \mathrm{~h}$ & $187 \pm 5.8$ & 0.57 & 25 & $43^{\mathrm{a}}$ & 1.23 & 20 \\
\hline $168 \mathrm{~h}$ & $187 \pm 17$ & 0.63 & 15 & $101^{\mathrm{a}}$ & 0.87 & 19 \\
\hline
\end{tabular}

${ }^{a}$ Single measurement. RSD: relative standard deviation; TCS: triclosan; $\mathrm{K}_{\mathrm{f}}$ : fiber-water partition coefficient.

fibers was still increasing until 7 days of exposure for both fiber length tested.

Besides seawater, further studies involving the portion of contaminants in porewater can be considered as a key process to understand the release and bioavailability ${ }^{14}$ of contaminants in aquatic systems. This investigation was already discussed in literature with good correlation results directly related with freely dissolved concentration 
using this matrix. ${ }^{17,18}$ Bioaccumulation studies involving TCS uptake were developed with an assimilation rate of $10 \%$ from spiked sediments after 28 days exposure ${ }^{27}$ or an uptake of $0.06 \%$ after 3 weeks exposure..$^{28}$ In our results, TCS uptake by $1 \mathrm{~cm}$ fiber length has a reduced depletion rate $(51 \%$ in $24 \mathrm{~h})$, indicating a better application in bioavailability studies as surrogate of organism's uptake. Besides $1 \mathrm{~cm}$ acrylate fiber, this TCS depletion rate can be reached using PDMS coating results. In this way, an ideal device used for bioavailability study needs to reach this deployment rate in the system. However, for depletion tests involving bioavailability in porewater, besides seawater measurements, the investigation of a minimum porewater/ sediment concentrations, as well as sorption behavior of these compounds in sediments, must be considered.

The advantages of acrylate fibers used in this study are the commercial availability and the results reproducibility, being an interesting passive sampler device for future studies in laboratory and in the environment. In the same way, it is also imperative, after fiber coating selection, the use of natural seawater instead artificial, once water properties/composition can have influence in uptake results, before application in the field. These studies must also involve other compounds commonly found in marine environment such as other endocrine disrupting chemicals as well as pharmaceutical compounds. The uptake capacity could also be checked in future studies using different lengths and coating thickness.

In this sense, SPME fibers deployment in seawater can provide a sorption/uptake behavior of organic microcontaminants, being useful as passive sampling devices or even for bioavailability studies. This is a promising research area where their use as passive samplers can reduce laboratory and field efforts and variability, and can substitute the use of organisms in bioavailability assays.

\section{Conclusions}

In this study, acrylate fibers has demostrated to be a promising use as passive sampling device for compounds with low-medium hidrophobicity. Their use as bioavailability prediction was also observed. Future experiments must involve different fiber thickness and sizes to improve the uptake capacity as well as the use of bioassays with target organisms, to compare contaminants uptake in bioavailability studies.

\section{Acknowledgments}

The authors thank FAPESP (process 2012/17898-7 and 2013/09437-2), CNPq (process 304586/2013-7) and FACTE for the financial support, and Fiberguide Industries for kindly supplying the fibers.

\section{References}

1. Ebele, A. J.; Abdallah, M. A. E.; Harrad, S.; Emerging Contam. 2017, 3, 1 .

2. Dhillon, G. S.; Kaur, S.; Pulicharla, R.; Brar, S. K.; Clédon, M.; Verma, M.; Surampalli, R. Y.; Int. J. Environ. Res. Public Health 2015, 12, 5657.

3. Karlsson, M. V.; Carter, L. J.; Agatz, A.; Boxall, B. A.; Environ. Sci. Technol. 2017, 51, 6965.

4. Dafforn, K. A.; Simpson, S. L.; Kelaher, B. P.; Clarck, G. F.; Komyakova, V.; Wong, C. K. C.; Johnston, E.; Environ. Pollut. 2012, 163, 207.

5. Anderson, K. A.; Hillwalker, W. E. In Encyclopedia of Ecology; Jorgersen, S. E.; Fath, B. D., eds.; Elsevier: Oxford, UK, 2008, p. 348.

6. Joyce, A. S.; Pirogovski, M. S.; Adams, R. A.; Lao, W.; Tsukada, D.; Cash, C. L.; Haw, J. F.; Maruya, K. A.; Chemosphere 2015, 127, 10 .

7. Alvarez, D. A.; Stackelberg, P. E.; Petty, J. D.; Huckins, J. N.; Furlong, E. T.; Zaugg, S. D.; Meyer, M. T.; Chemosphere 2005, 61,610 .

8. Vrana, B.; Mills, G. A.; Allan, I. J.; Dominiak, E.; Svenson, K.; Knutson, J.; Morrison, G.; Greenwood, R.; Trends Anal. Chem. 2005, 24, 845 .

9. Creusot, N.; Tapie, N.; Piccini, B.; Balaguer, P.; Porcher, J. M.; Budzinski, H.; Ait-Aissa, S.; Environ. Sci. Pollut. Res. 2013, 20, 2784.

10. Li, H.; Helm, P. A.; Metcalfe, C. D.; Environ. Toxicol. Chem. 2010, 29, 751.

11. Petty, J. D.; Orazio, C. E.; Huckins, J. N.; Gale, R. W.; Lebo, J. A.; Meadows, J. C.; Echols, K. R.; Cranor, W. L.; J. Chromatogr. A 2000, 879, 83 .

12. Kot, A.; Zabiegata, B.; Namiesnik, J.; Trends Anal. Chem. 2000, 19, 446.

13. Yang, Z. Y.; Maruya, K. A.; Greenstein, D.; Tsukada, D.; Zeng, E. Y.; Chemosphere 2008, 72, 1435.

14. Gschwend, P. M.; MacFarlane, J. K.; Reible, D. D.; Lu, X.; Hawthorme, S. B.; Nakles, D. V.; Thompson, T.; Environ. Toxicol. Chem. 2011, 30, 1288.

15. Ghosh, U.; Driscoll, S. K.; Burgess, R. M.; Jonker, M. T. O.; Reible, D.; Gobas, F.; Choi, Y.; Apitz, S.; Maruya, K. A.; Gala, W. R.; Mortimer, M.; Integr. Environ. Assess. Manage. 2014, 10,210 .

16. Maruya, K. A.; Lao, W.; Tsukada, D.; Diehl, D. W.; Chemosphere 2015, 137, 192.

17. Maruya, K. A.; Zeng, E. Y.; Tsukada, D.; Bay, S. M.; Environ. Toxicol. Chem. 2009, 28, 733.

18. Yang, Z. Y.; Zeng, E. Y.; Maruya, K. A.; Mai, B. X.; Ran, Y.; Chemosphere 2007, 66, 1408.

19. Lampert, D. J.; Lu, X.; Reible, D. D.; Environ. Sci.: Processes Impacts 2013, 5, 554. 
20. Lao, W.; Maruya, K. A.; Tsukada, D.; Anal. Chem. 2012, 84 , 9362.

21. Bayen, S.; Zhang, H.; Desai, M. M.; Ooi, S. K.; Kelly, B. C.; Environ. Pollut. 2013, 182, 1.

22. Morrison, G.; Chapman, G.; Supplemental Methods and Status Reports for Short-Term Saltwater Toxicity Tests; ERL Contrib. No. 1199; Environmental Research Laboratory, U.S. Environmental Protection Agency: Washington, DC, 1990, p. 127.

23. Cabrol, L.; Quéméneur, M.; Misson, B.; J. Microbiol. Methods 2017, 133, 62 .

24. Haftka, J. J. H.; Scherpenisse, P.; Jonker, M. T. O.; Hermens, J. L. M.; Environ. Sci. Technol. 2013, 47, 4455.
25. Kookana, R. S.; Shareef, A.; Fernandes, M. B.; Horae, S.; Gaylard, S.; Kumar, A.; Mar. Pollut. Bull. 2013, 74, 66.

26. Escarrone, A. L. V.; Caldas, S. S.; Primel, E. G.; Martins, S. E.; Nery, L. E. M.; Sci. Total Environ. 2016, 560, 218.

27. Perron, M. M.; Ho, K. T.; Cantwell, M. G.; Burgess, R. M.; Pelletier, M. C.; Environ. Toxicol. Chem. 2012, 31, 1861.

28. Ho, K. T.; Chariton, A. A.; Portis, L. M.; Cantwell, M. G.; Baguley, J. G.; Burgess, R. M.; Simpson, S.; Pelletier, M. C.; Perron, M. M.; Gunsch, C. K.; Bik, H. M.; Katz, D.; Kamikawa, A.; Environ. Toxicol. Chem. 2012, 32, 384.

Submitted: June 21, 2017

Published online: October 25, 2017 